\title{
RENDIMENTO E CONSERVAÇÃO DE CEBOLA ALTERADOS PELA DOSE E PARCELAMENTO DE NITROGÊNIO EM COBERTURA $^{(1)}$
}

\author{
Claudinei Kurtz(2), Paulo Roberto Ernani ${ }^{(3)}$, Jefferson Luís \\ Meirelles Coimbra ${ }^{(3)} \&$ Eder Petry ${ }^{(4)}$
}

\begin{abstract}
RESUMO
O rendimento e a conservação da cebola são influenciados pela disponibilidade de nitrogênio (N) no solo, o qual é requerido em grande quantidade. O presente trabalho objetivou avaliar o efeito de doses e do número de aplicações de $\mathrm{N}$ no estado nutricional das plantas, no rendimento e na conservação pós-colheita de bulbos de cebola. Foram realizados três experimentos, em campo, em Cambissolos catarinenses. Os tratamentos consistiram de uma combinação fatorial (4 x 3) envolvendo quatro doses de $\mathrm{N}\left(0,50,100 \mathrm{e} 200 \mathrm{~kg} \mathrm{ha}^{-1}\right)$ e três modos de aplicação (aos 45, aos 45 e 75, e aos 30, 60 e 90 dias após o transplante). De cada dose, $25 \%$ foram adicionados no plantio e o restante aplicado em uma ou dividido em duas ou três aplicações iguais. $O$ transplante das mudas foi sempre realizado na segunda quinzena de julho, e a colheita foi efetuada aproximadamente 115 dias depois. O rendimento de bulbos aumentou de forma quadrática com o aumento da quantidade de $\mathrm{N}$ aplicada. A dose de $\mathrm{N}$ estimada que proporcionou a máxima produtividade econômica variou de $249 \mathrm{~kg} \mathrm{ha}^{-1}$ em 2006/07, onde o solo era arenoso, a 116 e $142 \mathrm{~kg} \mathrm{ha}^{-1} \mathrm{em} \mathrm{2008/09} \mathrm{e} \mathrm{2009/10,} \mathrm{respectivamente,} \mathrm{em}$ solo mais argiloso. Os rendimentos máximos obtidos foram de 38,46 e $30 \mathrm{t} \mathrm{ha}^{-1}$ em 2006/07, 2008/09 e 2009/10, respectivamente, e as doses de $\mathrm{N}$ correspondentes à máxima produtividade econômica promoveram incrementos de $42,10 \mathrm{e} 17 \%$, respectivamente, no tratamento sem $\mathrm{N}$. O aumento do número de aplicações de $\mathrm{N}$ em cobertura, de uma para duas ou três, não alterou o rendimento e a conservação pós-colheita em nenhum ano. Em solos arenosos com baixo teor de matéria orgânica, é necessário aplicar maior quantidade de $\mathrm{N}$ para obter alto
\end{abstract}

\footnotetext{
(1) Pesquisa financiada pela FAPESC. Recebido para publicação em 2 de maio de 2011 e aprovado em 7 de março de 2012.

(2) Pesquisador da Empresa de Pesquisa Agropecuária e Extensão Rural de do Estado de Santa Catarina - Epagri. Estrada Geral Lageado Águas Negras, Caixa Postal 121, CEP 88400-000 Ituporanga (SC). E-mail: kurtz@epagri.sc.gov.br

(3) Professores da Universidade do Estado de Santa Catarina - UDESC. Av. Luiz de Camões 2090, CEP 88520-000 Lages (SC). Pesquisadores do CNPq. E-mails: prernani@cav.udesc.br; coimbrajefferson@cav.udesc.br

(4) Engo. Agrônomo da Ituprojetos Agrícolas e Ambientais. Rua Pres. Jucelino 237, CEP 88400-000 Ituporanga (SC). E-mail: ederpety@ yahoo.com.br
} 
rendimento de cebola do que em solos argilosos com médios teores de matéria orgânica. A adição de $\mathrm{N}$ ao solo pode alterar negativamente a conservação dos bulbos em anos chuvosos.

Termos de indexação: Allium cepa L., adubação nitrogenada, qualidade de bulbos.

\title{
SUMMARY: ONION YIELD AND BULB CONSERVATION AS AFFECTED
}

\author{
BY RATES AND SPLITTING OF SIDE-DRESSED NITROGEN
}

\begin{abstract}
Yield and conservation of onion bulbs are influenced by nitrogen $(N)$ availability in the soil, which is required in large amounts. This study aimed to evaluate the effect of $N$ application rates and splitting on the plant nutritional status, yield and conservation of onion bulbs after harvest. Three field experiments were carried out in Southern Brazilian Haplumbrepts. Treatments consisted of a factorial combination $(4 x 3)$ involving four $N$

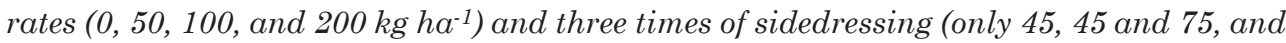
30,60 and 90 days after transplanting). Of each rate, $25 \%$ were applied at planting and the remaining was sidedressed all at once or equally divided in two or three times. Seedlings were always transplanted in the second half of July and the harvest occurred approximately 115 days later. Bulb yield increased quadratically with increasing $N$ rates. The best economic yield varied from $249 \mathrm{~kg} \mathrm{ha}^{-1}$ in 2006/07, in sandy soil, to 116 and $142 \mathrm{~kg} \mathrm{ha} \mathrm{g}^{-1}$ respectively in 2008/09 and 2009/10, in clayey soils. Maximum bulb yields were 38, 46 and $30 \mathrm{th} \mathrm{a}^{-1}$ respectively in 2006/07, 2008/09 and 2009/10, and $N$ levels corresponding to the best economic yield led to increases of 42,10 and $17 \%$, respectively, compared to the treatment with no N. Splitting $N$ rates had no effect on yield and bulb quality, regardless of the year. In sandy soils with low organic matter content, higher $N$ rates are required to achieve high onion yields than in clayey soils with medium organic matter content. In rainy years, $N$ applications may have negative effects on bulb conservation.
\end{abstract}

Index terms: Allium cepa L., nitrogen fertilization, bulb quality.

\section{INTRODUÇÃO}

A cebola (Allium cepa L.) é a terceira hortaliça mais importante economicamente no Brasil, sendo superada apenas pela batata e pelo tomate (Boeing, 2002). Santa Catarina é o Estado que mais produz cebola, com aproximadamente $33 \%$ do total. $\mathrm{Na}$ safra 2009/2010, o Estado produziu $454 \mathrm{mil}$ toneladas, com produtividade média de $21,6 \mathrm{t} \mathrm{ha}^{-1}$ (Epagri, 2010).

Tanto o rendimento como a sanidade e a qualidade dos bulbos de cebola são influenciados pela disponibilidade de $\mathrm{N}$ no solo. $\mathrm{O} \mathrm{N}$ é o segundo nutriente mais requerido por essa espécie, sendo superado somente pelo K. Na dinâmica do N no solo, a lixiviação constitui uma das principais perdas desse nutriente, principalmente em regiões de alta precipitação pluvial, como o sul do Brasil, e especialmente em solos arenosos, devido ao predomínio da forma de nitrato $\left(\mathrm{NO}_{3}{ }^{-}\right)$, que é altamente móvel no solo. Como a maioria dos solos possui essencialmente cargas elétricas negativas, acrescido ao fato de o nitrato não ser retido em fase sólida por nenhum mecanismo químico, sua lixiviação ocorre sempre que há percolação de água no perfil (Ernani, 2008). Devido à lixiviação, recomenda-se aplicar os fertilizantes nitrogenados duas ou mais vezes em cada ciclo de cultivo.

A cultura da cebola normalmente responde à adição de fertilizantes nitrogenados (Hassan, 1984; Buwalda \& Freeman, 1987; Greenwood et al., 1992). A dose de $\mathrm{N}$ que proporciona a máxima produtividade depende da cultivar (May et al., 2007) e de vários atributos do solo, principalmente dos teores de argila e de matéria orgânica (Magalhães, 1988; Vidigal, 2000), além das condições de cultivo (Batal et al., 1994), e normalmente situa-se entre 100 e $200 \mathrm{~kg} \mathrm{ha}^{-1}$ (Magalhães, 1988; Vidigal, 2000; May, 2006; Resende \& Costa, 2009). Entretanto, Batal et al. (1994) afirmam que alguns estudos têm indicado não haver incremento no rendimento de cebola pela adição de $\mathrm{N}$, mesmo em solos de textura arenosa. A exigência de $\mathrm{N}$ pela cebola aumenta a partir da metade do ciclo (Haag et al., 1970; 
Wiedenfeld, 1994) e, por isso, em situações com grande potencial de lixiviação, a maior parte desse nutriente deve ser aplicada nesse período (Caldwell et al., 1994; Batal et al., 1994).

Nos Estados de Santa Catarina e Rio Grande do Sul, a recomendação de $\mathrm{N}$ considera os teores de matéria orgânica (MO) do solo. Em solos com teores médios (25 a $\left.50 \mathrm{~g} \mathrm{~kg}^{-1}\right)$ e elevados $\left(>50 \mathrm{~g} \mathrm{~kg}^{-1}\right)$ de $\mathrm{MO}$, a recomendação para a cebola é de $10 \mathrm{~kg} \mathrm{ha}^{-1}$ no plantio, seguida de aplicações adicionais de $20 \mathrm{~kg} \mathrm{ha}^{-1}$, que devem ser efetuadas quando as plantas apresentarem sintomas de deficiência ou quando houver temperatura baixa e, ou, chuvas de alta intensidade (CQFSRS/SC, 2004). Para solos com menos de $25 \mathrm{~g} \mathrm{~kg}^{-1}$ de $\mathrm{MO}$, recomenda-se parcelar a dose de $\mathrm{N}$ em duas vezes, adicionando $50 \%$ por ocasião do transplante e o restante 45 dias depois, geralmente coincidindo com o início da bulbificação, e a dose máxima recomendada é de $95 \mathrm{~kg} \mathrm{ha}^{-1}$. Em anos de altas precipitações pluviais, parte do $\mathrm{N}$ adicionado por essa única aplicação pode ser lixiviada e comprometer a absorção durante a bulbificação, que é a época de maior demanda e ocorre entre 60 e 90 dias após o transplante.

$\mathrm{O}$ parcelamento do $\mathrm{N}$ ao longo do ciclo da cultura pode ser importante para aumentar a eficiência de uso do $\mathrm{N}$ aplicado. Maior número de aplicações em menores quantidades pode reduzir a lixiviação e a possibilidade de contaminação das águas subsuperficiais. Maiores doses aplicadas em maior número de parcelas proporcionaram maior produção de bulbos (Batal et al., 1994).

Este trabalho objetivou avaliar o efeito de doses e de parcelamentos de $\mathrm{N}$ em cobertura no estado nutricional das plantas, no rendimento e na conservação pós-colheita de bulbos de cebola.

\section{MATERIAL E MÉTODOS}

O presente trabalho foi constituído por três experimentos de campo, no município de Ituporanga, na região do Alto Vale do Itajaí, em Santa Catarina. $\mathrm{Na}$ safra 2006/2007, o experimento foi conduzido numa propriedade rural, em um Cambissolo Háplico distrófico de textura arenosa (Embrapa, 2009) que vinha sendo cultivado com cebola, em sucessão de culturas, durante vários anos. Nas safras 2008/2009 e 2009/2010, os experimentos foram conduzidos na Estação Experimental da Empresa de Pesquisa Agropecuária e Extensão Rural de Santa Catarina (EPAGRI), situada a $475 \mathrm{~m}$ de altitude, $27^{\circ} 22^{\prime} \mathrm{S}$ de latitude e $49^{\circ} 35^{\prime} \mathrm{W}$ de longitude, em um Cambissolo Háplico distrófico argiloso (Embrapa, 2009), onde a cebola é cultivada esporadicamente em sistema de rotação de culturas. Por ocasião da implantação dos experimentos, foram coletadas amostras de solo na profundidade de $0-20 \mathrm{~cm}$ para determinação dos atributos químicos (Quadro 1), de acordo com métodos descritos por Tedesco et al. (1995). O sistema de manejo do solo utilizado foi sempre o convencional, com lavração, gradagem e passagem de enxada rotativa restrita às linhas de plantio (faixa de $10 \mathrm{~cm}$ ), seguido de transplante manual das mudas de cebola.

Os tratamentos foram os mesmos para os três experimentos e consistiram de um esquema fatorial 4 x 3, envolvendo quatro doses de $\mathrm{N}(0,50,100 \mathrm{e}$ $200 \mathrm{~kg} \mathrm{ha}^{-1}$ ) e três épocas de aplicação da adubação de cobertura de cada dose, em delineamento experimental de blocos casualizados com quatro repetições. Nos tratamentos que receberam $\mathrm{N}$, $25 \%$ da quantidade total foi aplicada por ocasião do plantio, sendo o restante aplicado em uma, duas ou três vezes, em doses iguais. No tratamento com apenas um parcelamento, a adubação de cobertura foi realizada 45 dias após o transplante (DAT) das mudas; no tratamento com duas adubações de cobertura, elas foram feitas aos 45 e aos 75 DAT; no tratamento com três coberturas, o $\mathrm{N}$ foi aplicado aos 30, 60 e 90 DAT. Com o objetivo de evitar perdas por volatilização de amônia, usou-se nitrato de amônio $(32 \%$ de N) como fonte de N. As aplicações de $\mathrm{N}$ foram sempre realizadas a lanço, sobre a superfície do solo, sem incorporação. Na adubação que antecedeu o plantio, também foram adicionados

Quadro 1. Caracterização física e química do solo das áreas experimentais em amostras coletadas por ocasião da implantação dos experimentos

\begin{tabular}{|c|c|c|c|c|c|c|c|c|}
\hline Safra & $\mathrm{pH}-\mathrm{H}_{2} \mathrm{O}^{(1)}$ & $\mathrm{MO}^{(2)}$ & $\mathbf{P}$ & $\mathbf{K}$ & $\mathrm{Ca}$ & $\mathrm{Mg}$ & $\operatorname{CTC}^{(3)}$ & Argila \\
\hline & & $\mathrm{g} \mathrm{kg}^{-1}$ & $\mathrm{mg} \mathrm{kg}^{-1}$ & 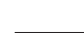 & - & & - & $\mathrm{g} \mathrm{kg}^{-1}$ \\
\hline $2006 / 07$ & 5,9 & 20 & 80 & 0,18 & 6,0 & 2,7 & 11,7 & 20 \\
\hline 2008/09 & 6,4 & 40 & 24 & 0,15 & 7,7 & 4,1 & 14,7 & 38 \\
\hline $2009 / 10$ & 5,7 & 38 & 21 & 0,26 & 6,4 & 3,3 & 14,3 & 35 \\
\hline
\end{tabular}

(1) Análises realizadas conforme métodos descritos por Tedesco et al. (1995). ${ }^{(2)}$ Matéria orgânica do solo. ${ }^{(3)}$ Capacidade de troca de cátions. 
$90 \mathrm{~kg} \mathrm{ha}^{-1}$ de $\mathrm{K}_{2} \mathrm{O}$, na forma de $\mathrm{KCl}\left(60 \%\right.$ de $\left.\mathrm{K}_{2} \mathrm{O}\right)$, e $160 \mathrm{~kg} \mathrm{ha}^{-1}$ de $\mathrm{P}_{2} \mathrm{O}_{5}$, na forma de superfosfato triplo (42\% de $\mathrm{P}_{2} \mathrm{O}_{5}$ ), distribuídos a lanço e incorporados com enxada rotativa. Não foi aplicado P na safra 2006/07, em razão dos valores elevados de $\mathrm{P}$ disponível encontrados no solo (80 $\left.\mathrm{mg} \mathrm{kg}^{-1}\right)$.

As unidades experimentais tinham 3,0 x 4,0 m, e todas as avaliações foram feitas na área útil central de $6,0 \mathrm{~m}^{2}$. As mudas de cebola da cultivar EMPASC 352-Bola Precoce foram transplantadas sempre na segunda quinzena de julho, na densidade de 10 plantas por metro linear, com espaçamento de $0,4 \mathrm{~m}$ entre as linhas, equivalente a 250.000 plantas ha ${ }^{-1}$.

O controle de plantas espontâneas, de pragas e de doenças foi efetuado por meio de pulverizações com produtos químicos registrados no Ministério da Agricultura para a cultura da cebola. No controle de plantas espontâneas, foram efetuadas três aplicações com herbicidas $\left(2,5 \mathrm{~L} \mathrm{ha}^{-1}\right.$ de pendimethalin; $1,0 \mathrm{~L} \mathrm{ha}^{-1}$ de ioxynil; e uma mistura de $50 \mathrm{~mL} \mathrm{ha}^{-1}$ de fenoxaprop-p-ethyl com $50 \mathrm{~mL} \mathrm{ha}^{-1}$ de clethodim) e uma capina manual. Para o controle de pragas, em especial do trips (Thrips tabaci Lind), foram realizadas três aplicações do inseticida deltametrina na dose de $4 \mathrm{~mL} \mathrm{ha}^{-1}$. Para o controle de doenças fúngicas, principalmente de míldio (Peronospora destructor) e alternária (Alternaria solani), foram realizadas quatro pulverizações com mistura dos seguintes fungicidas: $80 \mathrm{~g} \mathrm{ha}^{-1} \mathrm{de}$ metalaxyl $+1.280 \mathrm{~g} \mathrm{ha}^{-1}$ de mancozeb $+200 \mathrm{~mL} \mathrm{ha}^{-1}$ de tebuconazole.

$\mathrm{Na}$ primeira quinzena de outubro, por ocasião do início da bulbificação, foram coletadas amostras de folhas para avaliar o teor de nutrientes. Determinou-se a concentração de N, K, Ca e Mg de acordo com os métodos descritos por Tedesco et al. (1995). Nessa mesma fase, nas safras 2008/09 e 2009/10, foi avaliado o número de folhas, a altura das plantas e o número de folhas eretas.

A colheita dos bulbos foi realizada, em média, 115 dias após o transplante, quando aproximadamente $70 \%$ das plantas apresentaram tombamento da parte aérea (estalamento). Após serem arrancados, os bulbos permaneceram na lavoura sobre o solo por 14 dias, num processo denominado de pré-cura. Posteriormente, os bulbos foram separados em sadios e deteriorados, e em seguida efetuou-se a classificação comercial, pesagem e contagem. A classificação comercial foi feita pela medida do diâmetro, de acordo com a Portaria 529 do Ministério da Agricultura MAPA (1995). Os bulbos com diâmetro maior do que $50 \mathrm{~mm}$ foram armazenados em galpão, dentro de caixas plásticas, por um período de 135 dias para avaliação da perda pós-colheita.
A produção de máxima eficiência econômica foi estimada pelo cálculo da derivada das equações de regressão obtidas entre a quantidade de $\mathrm{N}$ aplicada e a produtividade, considerando o preço médio da cebola ( $\mathrm{R} \$ 0,61 \mathrm{~kg}^{-1}$ de bulbo) e do $\mathrm{N}$ oriundo do nitrato de amônio $\left(\mathrm{R} \$ 2,50 \mathrm{~kg}^{-1}\right.$ de $\left.\mathrm{N}\right)$ nas últimas cinco safras (2006 a 2010). Os três experimentos foram avaliados separadamente. O efeito dos fatores principais e da interação entre eles foi avaliado estatisticamente por meio da análise de variância; o efeito das doses de $\mathrm{N}$ foi avaliado por meio de análise de regressão. No fator parcelamento, quando a análise de variância mostrou haver significância, as médias foram comparadas pelo teste de Tukey $(\mathrm{p} \leq 0,05)$.

\section{RESULTADOS E DISCUSSÃO}

\section{Rendimento de bulbos}

$\mathrm{A}$ adição de $\mathrm{N}$ ao solo aumentou o rendimento de bulbos de cebola de forma quadrática, nas três safras (Figura 1a). A análise de variância indicou que não houve interação entre doses e número de vezes que o fertilizante nitrogenado foi aplicado nas adubações de cobertura, independentemente das variáveis avaliadas ou do ano agrícola. $\mathrm{Na}$ safra 2006/07, na qual o experimento foi realizado em solo arenoso com teor de MO de $20 \mathrm{~g} \mathrm{~kg}^{-1}$, a produtividade de bulbos aumentou de $26,7 \mathrm{t} \mathrm{ha}^{-1}$, no tratamento sem adição de $\mathrm{N}$, para $38,0 \mathrm{t} \mathrm{ha}^{-1}$ naquele que recebeu a maior dose de $\mathrm{N}\left(200 \mathrm{~kg} \mathrm{ha}^{-1}\right)$, representando incremento de $42 \%$, porém a dose estimada de $\mathrm{N}$ que proporcionaria o rendimento máximo foi de $265 \mathrm{~kg} \mathrm{ha}^{-1}$.

$\mathrm{Na}$ safra 2008/09, o rendimento aumentou de $42,0 \mathrm{t} \mathrm{ha}^{-1}$ para até $46,1 \mathrm{t} \mathrm{ha}^{-1}$, cujo incremento de $9,6 \%$ seria obtido pela adição de $124 \mathrm{~kg} \mathrm{ha}^{-1}$ de N. No ano seguinte, a produtividade máxima estimada foi de $30,2 \mathrm{t} \mathrm{ha}^{-1}$ e seria obtida pela adição de $153 \mathrm{~kg} \mathrm{ha}^{-1}$ de $\mathrm{N}$, com incremento de $16,5 \% \mathrm{em}$ relação ao tratamento em que não foi aplicado $\mathrm{N}$. Os incrementos proporcionados pela adição de $\mathrm{N}$ ao solo nessas safras foram menores do que aquele verificado em 2006/2007, provavelmente devido às diferenças na composição do solo entre as áreas experimentais, uma vez que o solo utilizado na safra 2006/2007 tinha menor teor de MO e mais areia do que o solo da área experimental das outras duas safras (Quadro 1). Tem sido verificado que a resposta da cebola à adição de $\mathrm{N}$ diminui com $\mathrm{o}$ aumento do teor de MO do solo (Machado et al., 1984; Lima et al., 1984), em função do aumento da liberação de $\mathrm{N}$ do solo para as plantas (Cantarella et al., 1992; Ernani, 2008). 
Por outro lado, as perdas de $\mathrm{N}$ por lixiviação também aumentam com o incremento da fração arenosa do solo (Sangoi et al., 2003), mas essa não foi a causa da maior resposta a $\mathrm{N}$ no solo mais arenoso, uma vez que na primeira safra, quando o experimento foi conduzido nesse solo, choveu metade ou menos que nas safras subsequentes (Quadro 2). Halvorson et al. (2002) verificaram que o ${ }^{15} \mathrm{~N}$ aplicado em maio e em junho na cultura da cebola irrigada foi detectado a $180 \mathrm{~cm}$ de profundidade em setembro, demonstrando expressiva movimentação do $\mathrm{NO}_{3}^{-}$no perfil do solo. O rendimento médio de cebola obtido nas três safras foi bem maior do que o rendimento médio catarinense e brasileiro, que nos últimos anos foi próximo de $20 \mathrm{t} \mathrm{ha}^{-1}$.

Assim como neste estudo, vários pesquisadores têm constatado aumento no rendimento de cebola pela adição de $\mathrm{N}$ ao solo, em diversos locais e condições de cultivo. Alguns exemplos mostram que para atingir $90 \%$ da produção máxima de bulbos comercializáveis foram necessários entre 180 e $200 \mathrm{~kg} \mathrm{ha}^{-1}$ de N, em solos com baixo teor de MO (6 e $14 \mathrm{~g} \mathrm{~kg}^{-1}$ ) de Minas Gerais (Vidigal, 2000), e entre 105 e $125 \mathrm{~kg} \mathrm{ha}^{-1} \mathrm{de} \mathrm{N}$, em um Latossolo argiloso (MO de $24 \mathrm{~g} \mathrm{~kg}^{-1}$ ) de São Paulo, dependendo da cultivar (May et al., 2007). Rodrigues (1992) constatou que, em solo de Minas Gerais com MO de $40 \mathrm{~g} \mathrm{~kg}^{-1}$, a dose de $120 \mathrm{~kg} \mathrm{ha}^{-1}$ de $\mathrm{N}$ foi a que proporcionou a maior produção total e comercial de bulbos. Em solos com teores baixos de MO, Vidigal (2000) observou que o incremento no rendimento variou de 39,4 a 96,3 kg para cada $\mathrm{kg}$ de $\mathrm{N}$ aplicado, dependendo da fonte, do sistema de parcelamento e do tipo de solo. Machado et al. (1984) aplicaram doses de N (0 a $160 \mathrm{~kg} \mathrm{ha}^{-1}$ ) em três cultivares cultivadas em dois Cambissolos catarinenses, com 35 e $51 \mathrm{~g} \mathrm{~kg}^{-1}$ de $\mathrm{MO}$, e verificaram que a resposta da cebola ao $\mathrm{N}$ foi inconstante, porém pequena para doses acima de $40 \mathrm{~kg} \mathrm{ha}^{-1}$, sendo os melhores resultados obtidos com $65 \mathrm{~kg} \mathrm{ha}^{-1}$ de N. Diferentemente dos resultados citados, alguns autores têm demonstrado não haver incremento no rendimento de cebola pela adição de N ao solo (Lima et al., 1984; Smittle, 1984; Asiegbu, 1989; Batal et al., 1994), e essas diferenças devem-se a fatores climáticos, à população de plantas e, principalmente, aos teores de MO do solo (Magalhães, 1988).

O cálculo do retorno econômico da produção de cebola em função da adubação nitrogenada mostrou que a máxima eficiência econômica seria atingida com a aplicação de 249, 116 e $142 \mathrm{~kg} \mathrm{ha}^{-1}$ de N, respectivamente nas safras 2006/07, 2008/09 e 2009/10. Considerando o preço médio pago ao produtor de cebola em Santa Catarina $\left(\mathrm{R} \$ 0,61 \mathrm{~kg}^{-1}\right.$ de bulbo) nos últimos cinco anos, seriam necessários apenas $4,13 \mathrm{~kg}$ de cebola para adquirir $1,0 \mathrm{~kg}$ de $\mathrm{N}$ usando como fonte o nitrato de amônio $\left(\mathrm{R} \$ 2,50 \mathrm{~kg}^{-1}\right.$ de $\mathrm{N}$ ).

\section{Peso e tamanho de bulbos}

$\mathrm{O}$ incremento nas doses de $\mathrm{N}$ aumentou de forma quadrática o peso médio dos bulbos de cebola, nas três safras (Figura 1b). Ele passou de 133, 169 e 102 g na testemunha que não recebeu N, para até 201,186 e $120 \mathrm{~g}$, que seriam obtidos pela adição de 283,112 e $156 \mathrm{~kg} \mathrm{ha}^{-1}$ de N, nas safras 2006/07, 2008/09 e 2009/10, respectivamente. O efeito do N no aumento do tamanho de bulbos seguiu a mesma tendência verificada no rendimento, apresentando incrementos de 51, 10 e $18 \%$ no peso máximo, respectivamente nas safras 2006/07, 2008/09 e 2009/10. Em solos do Nordeste brasileiro, a dose de $114 \mathrm{~kg} \mathrm{ha}^{-1}$ de $\mathrm{N}$ foi a que proporcionou maior peso de bulbos (Resende et al., 2008). Aumentos no peso de bulbos com o aumento na adição de $\mathrm{N}$ foram também obtidos por Hassan (1984), Machado et al. (1984), Batal et al. (1994) e May et al. (2007).

A obtenção de bulbos maiores, além de estar diretamente relacionada com o aumento no rendimento, também aumenta a lucratividade, pois bulbos com diâmetro inferior a $50 \mathrm{~mm}$ apresentam menor valor de mercado do que bulbos maiores. Os bulbos de peso médio, ao redor de 150 g, são os preferidos comercialmente. Bulbos de tamanho muito grande devem ser evitados, pois, além de terem menor aceitação comercial, são mais suscetíveis ao apodrecimento (Batal et al., 1994). Os tratamentos com as maiores doses de $\mathrm{N}$ proporcionaram bulbos grandes, principalmente nas duas primeiras safras (Figura 1b). Além da dose de $\mathrm{N}$, o tamanho dos bulbos pode ser controlado pela variação na população de plantas (Stoffella, 1996; Santos et al., 2000; Dellacecca \& Lovato, 2000); quanto maior a população de plantas, maior é a quantidade de $\mathrm{N}$ necessária para manter o peso de bulbos (May, 2006). Assim, para evitar bulbos de tamanho muito grande, que possuem restrições comerciais, como ocorreu nas safras 2006/07 e 2008/09, é necessário utilizar população de plantas maior do que aquela adotada nos experimentos (250.000 plantas ha-1).

$\mathrm{O}$ aumento da quantidade de $\mathrm{N}$ aplicada diminuiu a quantidade de bulbos com diâmetro inferior a $50 \mathrm{~mm}$ (Figura 1c). A quantidade de bulbos com esse diâmetro foi pequena na safra 2008/09 e bem maior na seguinte em função da menor produtividade. As doses de $\mathrm{N}$ que proporcionaram a menor quantidade de bulbos pequenos foram de 100 e $150 \mathrm{~kg} \mathrm{ha}^{-1}$, respectivamente nas safras 2008/09 e 2009/10. Bulbos com diâmetro inferior a $50 \mathrm{~mm}$ são mais difíceis de serem comercializados e possuem preço médio que varia de 50 a $70 \%$ em relação às classes de diâmetro maiores. May et al. (2007) e Resende et al. (2008) também obtiveram maior produção 

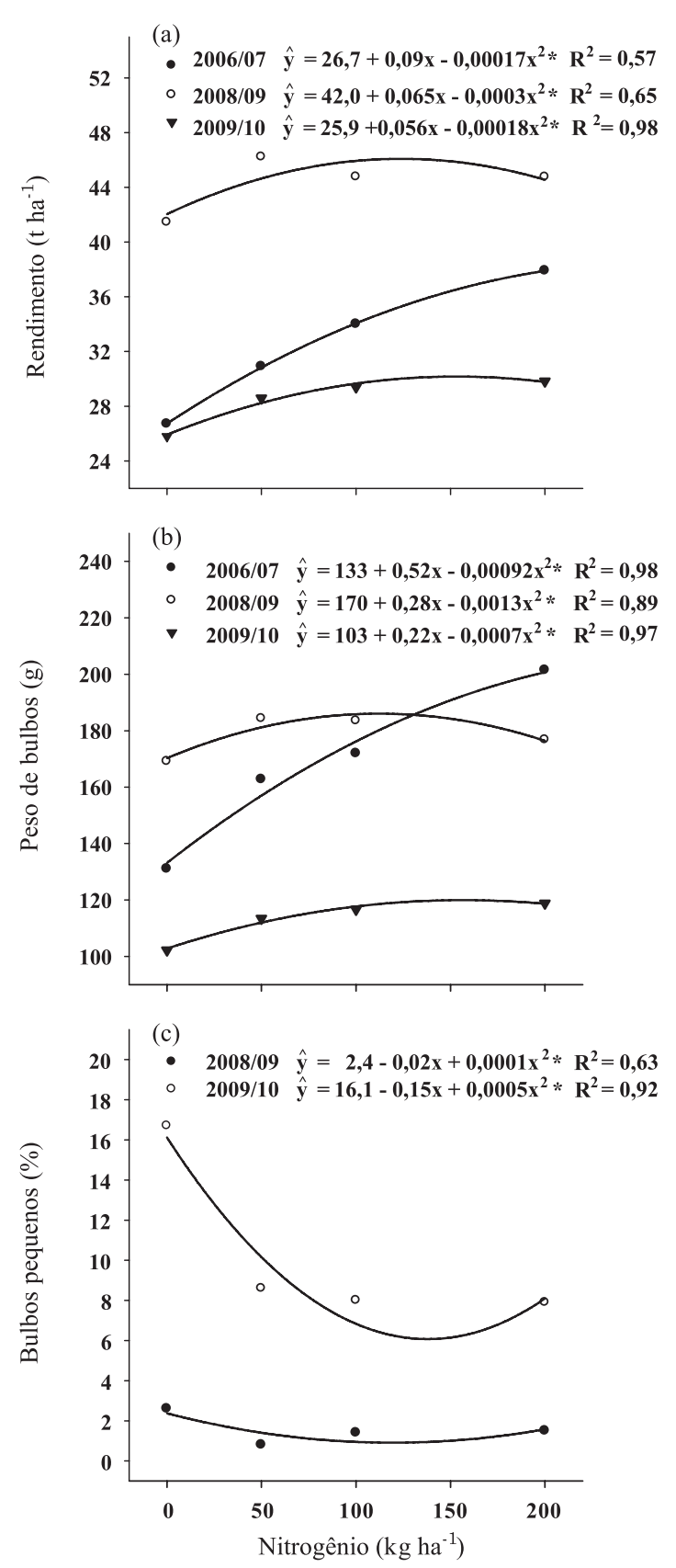

Figura 1. Rendimento (a), peso médio de bulbos (b) e bulbos pequenos (<50 mm) (c) de cebola em função da adição de doses crescentes de nitrogênio ao solo, em três safras. *: significativo $(\mathrm{p} \leq \mathbf{0 , 0 5})$.

de bulbos de diâmetro comercializável quando aumentaram as doses de $\mathrm{N}$.

\section{Crescimento e arquitetura das plantas}

$\mathrm{O}$ incremento nas doses de $\mathrm{N}$ aumentou o número de folhas por planta, nas duas safras em que esse atributo foi avaliado (Figura 2a). Na safra 2008/09, o aumento foi linear, passando de 9,1 folhas por planta, na testemunha, para 9,5 no tratamento com a maior dose aplicada (200 kg ha-1 de N). Na safra seguinte, o número de folhas aumentou de 6,7 para até o máximo de 7,6, que seria atingido pela adição de $146 \mathrm{~kg} \mathrm{ha}^{-1}$ de $\mathrm{N}$, situando-se próximo da dose de N que proporcionou o rendimento máximo de bulbos: $153 \mathrm{~kg} \mathrm{ha}^{-1}$ (Figura 1a). Incremento no número de folhas por planta de cebola pela adição de $\mathrm{N}$ foi também obtido por May (2006). O menor número de folhas por planta na última safra justifica, em parte, o menor rendimento obtido em relação à safra anterior (Figura 1a). A quantidade de folhas por planta está diretamente relacionada com o rendimento, que pode ser explicado pela maior área fotossintética e, principalmente, pelo fato de o bulbo ser formado pelo acúmulo de reservas na base da bainha de cada folha correspondente. Assim, quanto maior a quantidade de folhas, maior será o número de bainhas que sofrem engrossamento pelo acúmulo de reservas, aumentando o tamanho do bulbo.

Com o incremento da quantidade de $\mathrm{N}$ aplicada, a altura das plantas de cebola aumentou (Figura 2b), mas o número de folhas eretas diminuiu (Figura 2c). As alturas máximas foram de 82 e $72 \mathrm{~cm}$ para doses de 167 e $183 \mathrm{~kg} \mathrm{ha}^{-1}$ de $\mathrm{N}$, respectivamente nas safras 2008/09 e 2009/10. Para avaliar a arquitetura de plantas em função das doses crescentes de $\mathrm{N}$, mediu-se a quantidade de folhas eretas, ou seja, de folhas que não estavam tortas ou quebradas. A diminuição do número de folhas eretas com o aumento das doses de $\mathrm{N}$ ocorreu de forma quadrática na safra 2008/09 e de forma linear na safra seguinte (Figura 2c). O ideal é que as plantas tenham o maior número possível de folhas eretas, para interceptar melhor a incidência de luz e proporcionar melhor sanidade das plantas e conservação pós-colheita dos bulbos. Constata-se, portanto, que a adição de $\mathrm{N}$ é importante na produção de cebola, porém o excesso desse nutriente poder ser prejudicial.

\section{Perda de bulbos pós-colheita}

As perdas pós-colheita, avaliadas 135 dias após a armazenagem, aumentaram com o incremento da dose de $\mathrm{N}$ na safra $2008 / 09$, porém não foram influenciadas pela adição de $\mathrm{N}$ na safra seguinte (Figura 3). Em 2008/09, as perdas passaram de $19,5 \%$, na testemunha, para um máximo de $34,5 \%$, que ocorreu com a aplicação de $158 \mathrm{~kg} \mathrm{ha}^{-1}$ de N. Na safra 2009/10, as perdas pós-colheita não foram influenciadas pela adição de $\mathrm{N}$ e atingiram, em média, 20,8\%. As diferenças entre as duas safras nas perdas de pós-colheita provavelmente se devem às condições climáticas associadas ao teor de $\mathrm{N}$ nas plantas, sobretudo ao excesso de chuvas no final do ciclo da safra 2008/09 (Quadro 2). O excesso de chuvas, aliado a altas temperaturas, favorece 
a incidência de doenças bacterianas, que são as principais responsáveis pelo apodrecimento dos
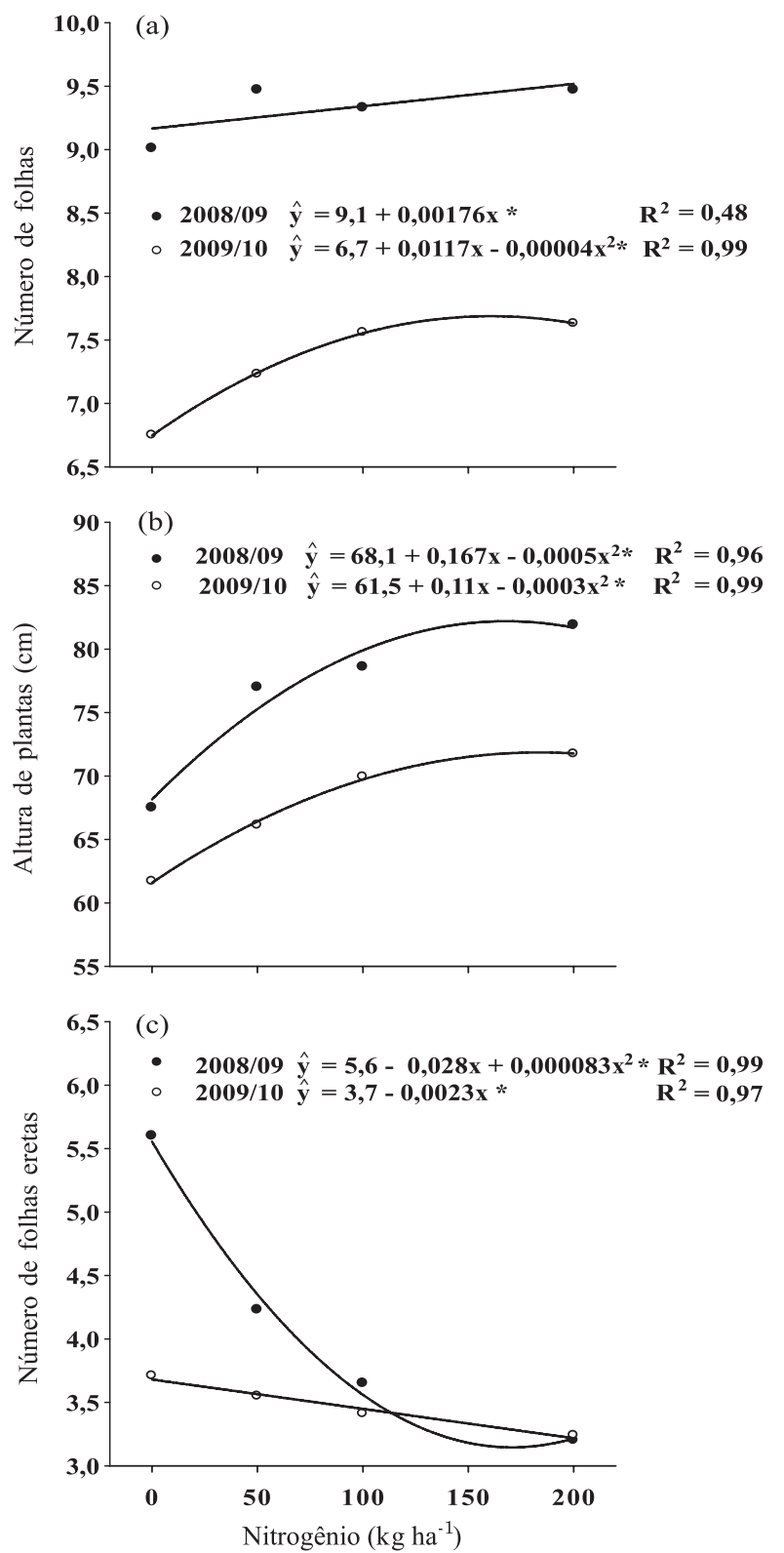

Figura 2. Número de folhas (a), altura de plantas (b) e número de folhas eretas (c) de cebola em função da adição de doses crescentes de nitrogênio ao solo, em duas safras. *: significativo $(\mathbf{p} \leq \mathbf{0 , 0 5})$. bulbos durante o armazenamento. Por isso, em anos com previsão de alta pluviosidade no final do ciclo, como ocorreu na safra 2008/09 (Quadro 2), é prudente adicionar doses menores de $\mathrm{N}$ quando se pretende armazenar a produção. Nesta safra, os ganhos de produtividade obtidos com a adição de $\mathrm{N}$ foram inferiores às perdas proporcionadas pelo $\mathrm{N}$ durante o armazenamento. Na safra 2009/2010, não houve excesso de chuvas no final do ciclo (Quadro 2) e a adição de $\mathrm{N}$ não alterou negativamente a armazenagem dos bulbos. Aumentos na perda póscolheita com o incremento das doses de $\mathrm{N}$ também foram obtidos por Singh \& Dhankhar (1991), mas Hussaini et al. (2000) não observaram efeitos da adição de $\mathrm{N}$ até a dose de $164 \mathrm{~kg} \mathrm{ha}^{-1}, 19$ semanas após a colheita.

\section{Teores de nutrientes na planta}

$\mathrm{O}$ aumento das doses de $\mathrm{N}$ adicionadas ao solo aumentou os teores de $\mathrm{N}$ nas folhas de cebola (Figura 4a). A concentração máxima de $\mathrm{N}$ foi de 40, 35 e $32 \mathrm{~g} \mathrm{~kg}^{-1}$ nas safras 2006/2007, 2008/09 e 2009/10; esses valores seriam obtidos pela adição de 237,136 e $150 \mathrm{~kg} \mathrm{ha}^{-1}$ de $\mathrm{N}$, respectivamente. Os teores adequados de $\mathrm{N}$ para a cebola situam-

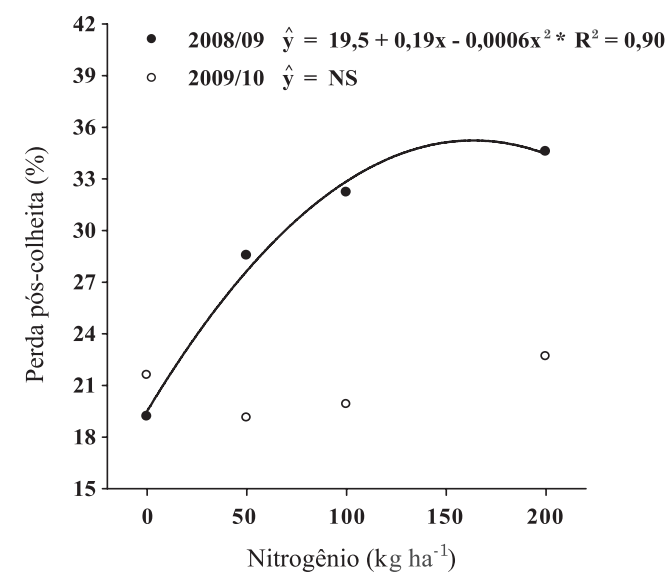

Figura 3. Perda pós-colheita de bulbos de cebola em função da adição de doses crescentes de nitrogênio ao solo, em duas safras. *: significativo ( $\leq \leq 0,05)$; NS: não significativo.

Quadro 2. Precipitação pluvial mensal e total $(\mathrm{mm})$ e número de dias com chuva durante o período de condução dos experimentos, em cada safra

\begin{tabular}{lrrrrrrr}
\hline Safra & Julho & Agosto & Setembro & Outubro & Novembro & Total & Dias com chuva \\
\hline $2006 / 07$ & 34 & 112 & 95 & 94 & 125 & 460 & 47 \\
$2008 / 09$ & 37 & 89 & 165 & 386 & 200 & 877 & 74 \\
$2009 / 10$ & 211 & 152 & 323 & 177 & 160 & 1023 & 73 \\
\hline
\end{tabular}

Fonte: Epagri/Ciram - Estação Meteorológica da Estação Experimental de Ituporanga (SC). 
se entre 19 e $40 \mathrm{~g} \mathrm{~kg}^{-1}$ (Reuter \& Robinson, 1988; Jones Júnior et al., 1991; Caldwell et al., 1994). $\mathrm{Na}$ safra 2006/07, as plantas que não receberam $\mathrm{N}$ apresentaram $28 \mathrm{~g} \mathrm{~kg}^{-1}$ nas folhas, e mesmo assim houve resposta à adição de $\mathrm{N}$. Nesta safra, as chuvas foram bem distribuídas (Quadro 2), o que deve ter contribuído para uma provável menor lixiviação de $\mathrm{N}$.

Os teores de $\mathrm{K}$ e Ca no tecido foliar aumentaram com o incremento das doses de $\mathrm{N}$ nas safras 2006/07 e 2008/09, porém não foram alterados na safra 2009/10 (Figura 4b,c). Os valores de Mg aumentaram linearmente com o aumento da dose de $\mathrm{N}$ na safra 2006/07, mas não foram alterados nas duas safras seguintes (Figura 4d). Os teores de $\mathrm{K}, \mathrm{Ca}$ e $\mathrm{Mg}$ não foram alterados pelo incremento das doses de N na safra 2009/10, provavelmente devido ao excesso de chuvas no período, o que pode ter diluído esses elementos na solução do solo, principalmente no mês de setembro, época em que ocorre o maior desenvolvimento vegetativo da cultura (Quadro 2). O aumento da absorção dos cátions $\mathrm{Ca}, \mathrm{Mg}$ e $\mathrm{K}$ decorrente do aumento da disponibilidade de $\mathrm{N}$, verificado no presente estudo (safras 2006/07 e 2008/09), pode ter ocorrido pelo fato de o $\mathrm{N}$ encontrar-se no solo fundamentalmente na forma de $\mathrm{NO}_{3}{ }^{-}$. A presença de $\mathrm{NO}_{3}{ }^{-}$pode ter favorecido a formação de pares iônicos com $\mathrm{Ca}$, $\mathrm{Mg}$ e $\mathrm{K}$ e, consequentemente, a absorção desses nutrientes, ou ainda ter promovido a necessidade de maior absorção de cátions para compensar o controle interno das cargas elétricas.

\section{Efeito do parcelamento do nitrogênio}

Como não houve interação entre as doses de $\mathrm{N}$ e o número de vezes em que o nutriente foi aplicado em cobertura, para a maioria das variáveis avaliadas, os dados apresentados no quadro 3 representam as médias das doses dentro de cada parcelamento. Somente houve influência do parcelamento do N nos teores de Ca e Mg na safra 2006/07 e no número de folhas eretas na safra 2008/09, onde ambos aumentaram com o maior número de aplicações na adubação de cobertura. Sá et al. (2004) também verificaram que o parcelamento do $\mathrm{N}$ não alterou o rendimento e a conservação dos bulbos.
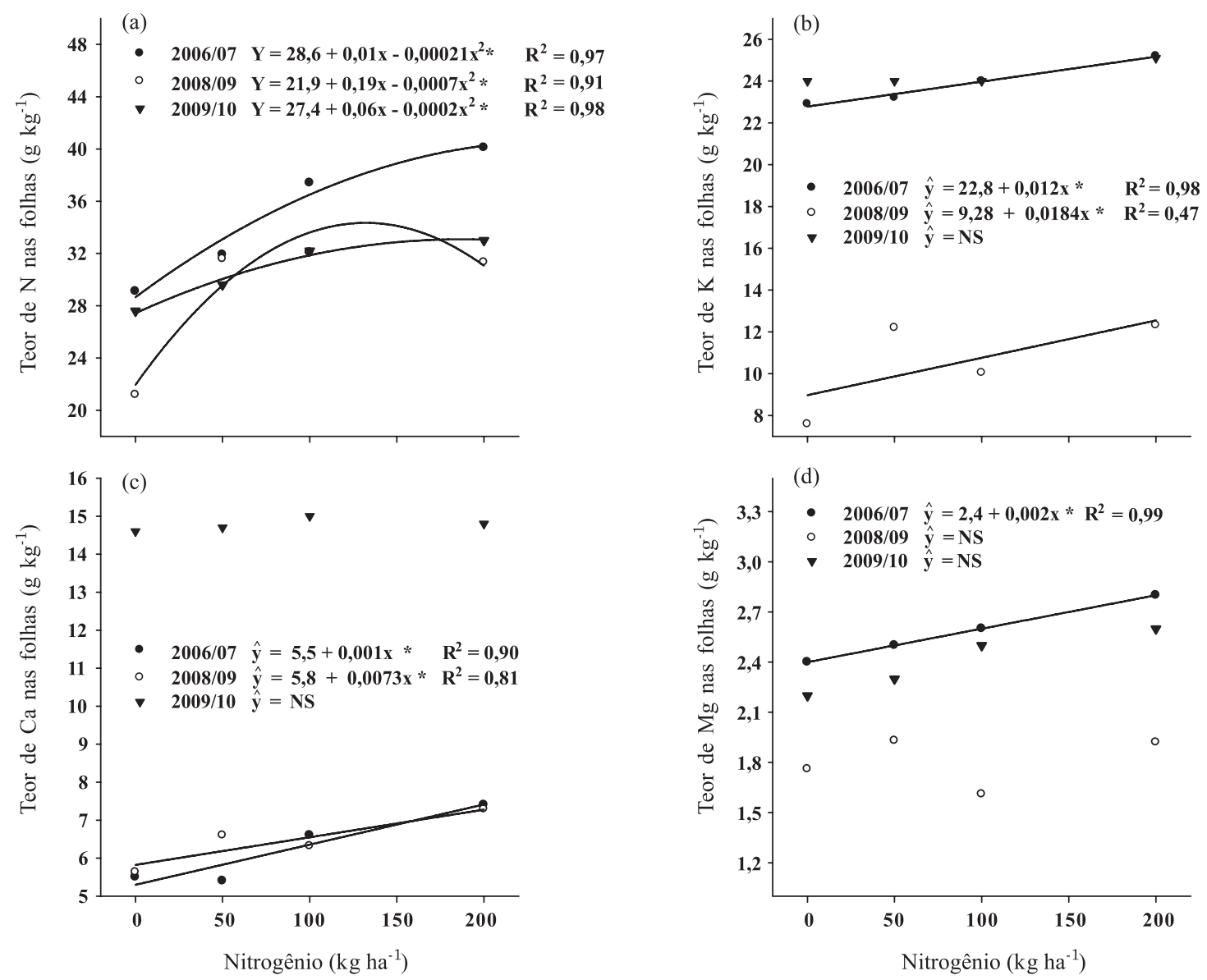

Figura 4. Teor de nitrogênio (a) potássio (b), cálcio (c) e magnésio (d) nas folhas de cebola em função da adição de doses crescentes de nitrogênio ao solo, em duas safras. *: significativo $(p \leq 0,05)$; NS: não significativo. 
Quadro 3. Rendimento de bulbos, morfologia das plantas, teores foliares de nutrientes e perdas póscolheita dos bulbos em função do parcelamento de doses de $\mathrm{N}$ na cultura da cebola, em três safras

\begin{tabular}{|c|c|c|c|}
\hline \multirow{2}{*}{ Variáveis } & \multicolumn{3}{|c|}{ Parcelamento } \\
\hline & Base +1 & Base +2 & Base +3 \\
\hline \multicolumn{4}{|c|}{ Safra 2006/07 } \\
\hline Rendimento (t ha-1) & 32,2 & 33,4 & 31,4 \\
\hline Peso médio dos bulbos (g) & 163 & 173 & 164 \\
\hline Teor de $\mathrm{N}$ foliar $\left(\mathrm{g} \mathrm{kg}^{-1}\right)$ & 33,4 & 35,3 & 35,2 \\
\hline Teor de Ca foliar $\left(\mathrm{g} \mathrm{kg}^{-1}\right)$ & $6,0 \mathrm{~b}$ & $6,5 \mathrm{ab}$ & $6,6 \mathrm{a}$ \\
\hline Teor de Mg foliar $\left(\mathrm{g} \mathrm{kg}^{-1}\right)$ & $2,4 \mathrm{~b}$ & $2,6 \mathrm{ab}$ & $2,8 \mathrm{a}$ \\
\hline Teor de K foliar $\left(\mathrm{g} \mathrm{kg}^{-1}\right)$ & 23,8 & 23,8 & 23,9 \\
\hline \multicolumn{4}{|c|}{ Safra 2008/09 } \\
\hline Rendimento (t ha $\left.{ }^{-1}\right)$ & 43,6 & 43,9 & 45,3 \\
\hline Peso médio bulbos (g) & 169 & 178 & 179 \\
\hline $\mathrm{N}$ foliar $\left(\mathrm{g} \mathrm{kg}^{-1}\right)$ & 29,8 & 29,5 & 27,8 \\
\hline Ca foliar $\left(\mathrm{g} \mathrm{kg}^{-1}\right)$ & 6,32 & 6,49 & 6,56 \\
\hline Mg foliar $\left(\mathrm{g} \mathrm{kg}^{-1}\right)$ & 1,75 & 1,91 & 1,76 \\
\hline $\mathrm{K}$ foliar $\left(\mathrm{g} \mathrm{kg}^{-1}\right)$ & 10,55 & 10,42 & 11,39 \\
\hline Altura de planta (cm) & 77,3 & 76,0 & 75,4 \\
\hline Número de folhas & 9,3 & 9,4 & 9,3 \\
\hline Número de folhas eretas & $3,86 \mathrm{~b}$ & $4,14 \mathrm{ab}$ & $4,51 \mathrm{a}$ \\
\hline Perda pós-colheita (\%) & 29,4 & 29,0 & 27,4 \\
\hline Bulbos < 50 mm (\%) & 1,7 & 1,7 & 1,3 \\
\hline \multicolumn{4}{|c|}{ Safra 2009/10 } \\
\hline Rendimento (t ha-1) & 27,7 & 28,3 & 29,2 \\
\hline Peso médio bulbos (g) & 110 & 112 & 117 \\
\hline $\mathrm{N}$ foliar $\left(\mathrm{g} \mathrm{kg}^{-1}\right)$ & 29,8 & 32,3 & 29,6 \\
\hline Ca foliar $\left(\mathrm{g} \mathrm{kg}^{-1}\right)$ & 14,9 & 14,6 & 14,8 \\
\hline Mg foliar $\left(\mathrm{g} \mathrm{kg}^{-1}\right)$ & 2,6 & 2,4 & 2,2 \\
\hline $\mathrm{K}$ foliar $\left(\mathrm{g} \mathrm{kg}^{-1}\right)$ & 24,5 & 24,3 & 24,1 \\
\hline Altura de planta $(\mathrm{cm})$ & 67,0 & 67,5 & 67,6 \\
\hline $\mathrm{N}^{\mathrm{o}}$ de folhas & 7,2 & 7,3 & 7,4 \\
\hline $\mathrm{N}^{\circ}$ de folhas eretas & 3,42 & 3,51 & 3,51 \\
\hline Perda pós-colheita (\%) & 20,9 & 21,5 & 20,0 \\
\hline Bulbos < 50 mm (\%) & 11,2 & 10,5 & 9,2 \\
\hline
\end{tabular}

Base $+1=25 \%$ da dose de $\mathrm{N}$ no transplante e $75 \%$ aos 45 dias após o transplante (DAT); Base $+2=25 \%$ da dose no transplante, $37,5 \%$ aos 45 DAT e 37,5 \% aos 75 DAT; Base $+3=25 \%$ da dose no transplante e aos 30, 60 e 90 DAT. Médias seguidas de mesma letra ou desprovidas de letra, na linha, não diferem entre si pelo teste de Tukey a $5 \%$.

Ao contrário dos resultados obtidos neste estudo, alguns autores demonstraram que altas doses aplicadas em maior número de vezes proporcionam maiores produções de cebola (Batal et al., 1994; Vidigal, 2000). Machado et al. (1984), trabalhando com dois solos da região de Ituporanga, SC, verificaram que o melhor rendimento foi obtido com a adubação nitrogenada dividida em três parcelas, sendo um terço no plantio, um terço aos 30 DAT e um terço aos 60 DAT. A recomendação atual para os Estados do RS e SC (CQFSRS/SC, 2004) é de parcelamento do $\mathrm{N}$, pois sugere que a adubação de cobertura com $\mathrm{N}$ seja feita aos $45 \mathrm{DAT}$, com o objetivo de promover alta disponibilidade de $\mathrm{N}$ na segunda metade do ciclo da cultura. Em relação a essa recomendação, tem-se que considerar que, quando for necessário adicionar doses elevadas de N, uma única aplicação pode estimular demasiadamente o crescimento vegetativo das plantas em detrimento do tamanho dos bulbos.

\section{CONCLUSÕES}

1. O rendimento de cebola aumentou com a adição de $\mathrm{N}$, e as doses que proporcionaram o maior retorno econômico variaram com a safra, desde 116 até $249 \mathrm{~kg} \mathrm{ha}^{-1}$ de $\mathrm{N}$.

2. O parcelamento da adubação nitrogenada não influenciou o rendimento e a conservação de bulbos, 
mas as perdas pós-colheita aumentaram com o incremento das doses de $\mathrm{N}$ em anos mais chuvosos.

3. Em solos arenosos e com baixo teor de matéria orgânica, é necessário aplicar maiores quantidades de N para obtenção de altos rendimentos de cebola do que em solos de textura média e com teores médios de matéria orgânica.

\section{LITERATURA CITADA}

ASIEGBU, J.E. Response of onion to lime and fertilizer $\mathrm{N}$ in a tropical Ultisol. Trop. Agric., 66:161-166, 1989.

BATAL, K.M.; BONDARI, K.; GRANBERRY, D.M. \& MULLINIX, B.G. Effects of source, rate, and frequency of $\mathrm{N}$ application on yield, marketable and rot incidence of sweet onion (Allium cepa L. cv. granex-33). J. Hortic. Sci., 69:10431051, 1994.

BOEING, G. Fatores que afetam a qualidade da cebola na agricultura familiar catarinense. Florianópolis, Instituto CEPA/SC, 2002. 88p.

BUWALDA, J.G. \& FREEMAN, R.E. Effects of nitrogen fertilizers on growth and yield of potato (Solanum tuberosum L. 'llam hardy'), onion (Allium cepa L. 'pukekohe longkeeper'), garlic (Allium sativum L. 'y strain') and hybrid squash (Curcubita maxima L. 'delica'). Sci. Hortic., 32:161-173, 1987.

CALDWELL, J.O.N.; SUMNER, M.E. \& VAVRINA, C.S. Development and testing of preliminary foliar DRIS norms for onions. HortScience, 29:1501-1504, 1994.

CANTARELLA, H.; ABREU, C.A. \& BERTON, R.S. Fornecimento de nutrientes pela matéria orgânica do solo. In: GUERRINI, I.A. ed. ENCONTRO SOBRE MATÉRIA ORGÂNICA DO SOLO: PROBLEMAS E SOLUÇÕES, Botucatu, 1992. Anais... Botucatu, UNESP, 1992. p.63-122.

COMISÃO DE QUÍMICA E FERTILIDADE DO SOLO CQFSRS/SC. Manual de adubação e calagem para os Estados do Rio Grande do Sul e de Santa Catarina. 10.ed. Porto Alegre, Sociedade Brasileira de Ciência do Solo/ Núcleo Regional Sul/ Universidade Federal do Rio Grande do Sul, 2004. 394p.

DELLACECCA, V. \& LOVATO, A.F.S. Effects of different plant densities and planting systems on onion (Allium cepa L.) bulb quality and yield. Acta Hortic., 533:197-203, 2000.

EMPRESA BRASILEIRA DE PESQUISA AGROPECUÁRIA EMBRAPA. Sistema brasileiro de classificação de solos. Brasília, 2009. 412p.

EMPRESA DE PESQUISA AGROPECUÁRIA E EXTENSÃO RURAL DE SANTA CATARINA - EPAGRI. Síntese anual da Agricultura de Santa Catarina 2009-2010. Florianópolis, 2010. 315p.

ERNANI, P.R. Química do solo e disponibilidade de nutrientes as plantas. Lages, O Autor, 2008. 230p.
GREENWOOD, D.J.; NEETESON, J.J.; DRAYCOTT, A.; WIJNEN, G. \& STONE, D. Measurement and simulation of the effects of $\mathrm{N}$-fertilizer on growth, plant composition and distribution of soil mineral-N in nationwide onion experiments. Fert. Res., 31:305-318, 1992.

HAAG, H.P.; HOMA, P. \& KIMOTO, T. Nutrição mineral de hortaliças: VIII absorção de nutrientes pela cultura da cebola. Anais ESALQ, 27:143-153, 1970.

HALVORSON, A.D.; FOLLETT, R.F.; BORTOLO, M.F. \& SCHWEISSING, F.C. Nitrogen fertilizer use efficiency of furrow-irrigated onion and corn. Agron. J., 9:442-449, 2002.

HUSSAINI, M.A.; AMANS, E.B. \& RAMALAN, A.A. Yield, bulb size distribution and storability of onion (Allium cepa L.) under different levels of $\mathrm{N}$ fertilization and irrigation regime. Trop. Agric., 77:145-149, 2000.

HASSAN, M.S. Effects of frequency of irrigation and fertilizer nitrogen on yield and quality of onions (Allium cepa L.) in the arid tropics of Sudan. Acta Hortic., 143:341-346, 1984.

JONES JÚNIOR, J.B.; WOLF, B. \& MILLS, H.A. Plant analysis an analysis handbook: A practical sampling, preparation, analysis and interpretation guide. Athens, Micro-Macro, 1991. 213p.

LIMA, J.A.; BUSO, J.A.; SOUZA, A.F.; MAKISHIMA, N.; JUNQUEIRA, J.G.O; FERREIRA, P.E. \& FILHO, J.C. Produção de cebola em função de níveis de aplicação de nitrogênio e fósforo. Hortic. Bras., 2:12-14, 1984.

MINISTÉRIO DA AGRICULTURA, ABASTECIMENTO E REFORMA AGRÁRIA - MAPA. Diário Oficial da República Federativa do Brasil. Brasilia, Seção 1, p.13513. 1995. (Portaria n. 529)

MACHADO, M.O.; VIZZOTTO, V.J.; LANZAR, E.A.; ECHEVERRIA, L.C.R.; CAVALLAZZI, M.R. \& MORAES, O. Adubação para a cultura da cebola na região do Alto Vale do Itajaí, Santa Catarina. Florianópolis, EMPASC, 1984. 17p. (EMPASC, Boletim Técnico, 26)

MAGALHÃES, J.R. Nutrição mineral da cebola. In: CHURATAMASCA, M.G.C. \& CANALEZ, J.I., eds. SEMINÁRIO NACIONAL DA CEBOLA, 3., Piedade, 1988. Anais... Jaboticabal, Escola Superior de Agricultura Luiz de Queiroz, 1988. p.93-118.

MAY, A. Desempenho de híbridos de cebola em função da população de plantas e fertilização nitrogenada e potássica. Jaboticabal, Universidade Estadual Paulista, 2006. 142p. (Tese de Doutorado)

MAY, A.; CECÍLIO FILHO, A.B.; PORTO, D.R.Q.; VARGAS, P.F. \& BARBOSA, J.C. Produdividade de híbridos de cebola em função da população de plantas e da fertilização nitrogenada e potássica. Hortic. Bras., 25:53-59, 2007.

RESENDE, G.M. \& COSTA, N.D. Produtividade e armazenamento de cebola (Allium Cepa L.) submetida a doses de nitrogênio e potássio via fertirrigação em cultivo de verão. Ci. Agrotec., 33:1314-1320, 2009. 
RESENDE, G.M.; COSTA, N.D. \& PINTO, J.M. Produtividade e qualidade pós-colheira de cebola adubada com doses crescentes de nitrogênio e potássio. Hortic. Bras., 26:388$392,2008$.

REUTER, D.J. \& ROBINSON, J.B. Plant analysis: An interpretation manual. Melbourne, Inkata Press, 1988. $218 \mathrm{p}$.

RODRIGUES, A.G. Idade de mudas e doses de nitrogênio influenciando a bulbificação da cebola (Allium cepa L.) no cultivo de verão. Viçosa, MG, Universidade Federal de Viçosa, 1992. 77p. (Tese de Mestrado)

SÁ, G.D.; BARTH, G.; REGHIN, M.Y. \& CAIRES, E.F. Influência de doses e épocas de aplicação de nitrogênio na produção e pós-colheita da cultura da cebola. In: CONGRESSO BRASILEIRO DE OLERICULTURA, 44., 2004; Hortic. Bras., 22, 2004. Suplemento. CD ROM.

SANGOI, L.; ERNANI, P.R.; LECH, V.A. \& RAMPAZZO, C. Lixiviação de nitrogênio afetada pela forma de aplicação de uréia e manejo dos restos culturais de aveia em dois solos com texturas contrastantes. Ci. Rural, 33:65-70, 2003.

SANTOS, H.S.; TANAKA, M.T.; WATANABE, S.H.; ARANTES P.A.Z. \& IVONE T.T. Produção de cebola em função de tamanho de muda e espaçamento. Hortic. Bras., 18:556$557,2000$.
SINGH, J. \& DHANKHAR, B.S. Effect of nitrogen, potash and zinc on storage loss of onion bulbs (Allium cepa L.). Veg. Sci., 18:16-23, 1991.

SMITTLE, D.A. Responses of onions to sulfur and nitrogen fertilization. Georgia, The University of Georgia College of Agriculture Experiment Station, 1984. (Res. Rep., 455)

STOFELLA, P.J. Planting arrangement and density of transplants influence sweet spanish onion yields end bulb size. Hortscience, 7:1129-1130, 1996.

TEDESCO, M.J.; GIANELLO, C.; BISSANI, C.A. \& BOHNEN, H. Análise de solo, plantas e outros materiais. 2.ed. Porto Alegre, Universidade Federal do Rio Grande do Sul, 1995. 174p. (Boletim Técnico, 5)

VIDIGAL, S.M. Adubação nitrogenada de cebola irrigada cultivada no verão: Projeto Jaíba, Norte de Minas Gerais. Viçosa, MG, Universidade Federal de Viçosa, 2000. 136p. (Tese de Doutorado)

WIEDENFELD, R. Nitrogen rate and timing effects on onion growth and nutrient uptake in a subtropical climate. Subtrop. Plant Sci., 46:32-37, 1994. 
